and moisture, undertaken at the instance of the War Metallurgy Committee of the National Research Council, led to the use as coating of a silicone paste originated by a fellowship of the Corning Glass Works. This fellowship has now been returned to work on porcelain enamels and has already led to the development of a high-titanium cover-coat enamel of very high opacity and resistance to acid. Another fellowship has been concerned with the reactions occurring during the sintering of iron powder compacts, while the American Iron and Steel Institute's multiple fellowship on acid recovery has completed eight years study, in co-operation with public health officials and industry, of waste pickle liquor. A multiple fellowship on magnesium is concerned with fundamental studies on magnesium and its alloying properties, with the prime purpose of producing alloys with superior properties. New nickel compounds and catalysts of special promise are being prepared under another project, and evaluated in co-operative programmes with industrial and government laboratories. This inclusive multiple fellowship is sponsored by the International Nickel Co.

Work in coal chemistry has led to the discovery that the gradual deterioration in the quality of re-cycle benzene is due to the preferential accumulation of paraffins. Many advances have been made in gas by-products, and a thorough study made of the polymerization of vinylnaphthalene which, contrary to published statements, is found to be a rapid process. New processes for purifying benzene, a novel type of 1 -in. laboratory column, and a universal type 3 -in. fractionating column are other achievements in this field, which includes a broad programme on alkylation and dealkylation from which the process of ethylating benzene at Koluta came.

Work in petroleum technology has included fundamental theoretical studies of distillation, particularly of rectification processes, and investigations on the physical properties of petroleum waxes, the mechanism of catalytic reactions and the nature and structure of catalyst surfaces. New and improved lubricants have been developed for aviation instruments as well as new testing methods for such products, and the report includes some information on the synthetic lubricants developed under the organic synthesis multiple fellowship of the Carbide and Carbon Chemicals Corporation, which has now operated continuously for thirty-two years. Progress in applications of 'Vinylite' resins from dispersions has been accelerated, and extensive studies of the effect of the composition of the liquid vehicle on the viscosity of the dispersion have provided a sound technical basis for formulating the coatings. Investigation of the chemistry of allyl compounds has led to industrial processes for 2:3-dichloropropanol, 3-chloro-1 : 2-propanediol and epichlorohydrin ; also phenylmorpholine has been produced on a sufficient scale for development. Military requirements initiated researches for non-ionic surface-active materials, and the vitamin section of the Heinz multiple fellowship on food varieties has thrown light on the effects of storage on the vitamin content of regular and fortified strained foods. The value of yeast as a therapeutic agent and as a source for vitamins, and the improvement of malt processing, have also been investigated.

A programme assigned to the Institute by the Air-Sea Rescue Agency of the Armed Services has led to the development of a treated superfine "Fiberglas" which promises to replace kapok for use in life-jackets on all naval vessels, and also for other purposes where its fire-proof qualities are of first importance. Careful studies on methods of evaluating buoyancy and of the role of packing density and column heights have led to a broader understanding of the mode of function of fibrous buoyant materials. Correlated studies of the physical and chemical properties of cotton fibres are also in progress, and during the War a continuous programme of testing threads and tapes for their ability to resist tropical conditions was carried out. A new field is being opened up in the use of recovered synthetic fibres to make textiles with desirable properties of their own. The utilization of industrial. proteins, including stabilized zein resins, as shellac substitutes, and the industrial uses of a chemically modified zein, the development of improved catalysts for the synthesis of butadiene from ethyl alcohol and of organic coating compositions for lining the wing tanks of aeroplanes as well as for steel to permit its use under conditions of severe corrosion, have all received attention; while investigations on the organosilicon compounds have led to the use of polysiloxane fluids as anti-foaming agents in petroleum products and moulding rubber and organic plastics.

Besides referring to the work of the fellowship on chemical hygiene, particularly in the study of newly available chemicals, from the point of view of hazards to health, the report includes notes on the Industrial Hygiene Foundation, which has strengthened its staff of specialists and completed a study of the control of sweeping dust in the pottery industry and of the technique of determining the safe limits of silica content in industrial dusts. Reference is again made to the synthesis of new antimalarial drugs, particularly hydroxyethyl analogues of the pamoquine series, involving the synthesis of 8-amino-6-hydroxyethoxyquinoline and the use of a new hydroxyethyl. ating agent, by the Department of Research in Pure Chemistry. An examination of the lepidyl carbinols, the preparation of 4-( $p$-dialkylaminobenzylidene)- and 4-( $p$-dialkylaminobenzyl)-aminoquinolines and the function of alloxan in causing experimental diabetes in animals, in the course of which two colour tests for alloxan have been developed, are other subjects under investigation in the Department.

\section{ONTARIO RESEARCH FOUNDATION}

\section{ANNUAL REPORT FOR 1945}

$\mathrm{T}$ THE annual report for 1945 of the director of research of the Ontario Research Foundation

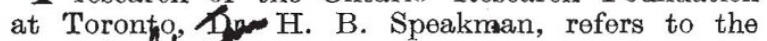
transitfon werrod through which the Foundation passfycing that year. Steps taken soon after the Wonthatfon of hostilities to restore to normal the Quilable space enabled the Foundation to respond to the increased demand for fellowship facilities, and before the close of the year the available laboratory space was fully occupied. Available statistics show that there are about eleven thousand industrial units in Ontario, of which only three hundred are large enough to justify the maintenance either of a research laboratory or a fellowship unit at the Foundation, and some of these consist of branch companies looking to a parent company in the United States for research and technical direction. 
Besides the twenty fellowships which tax the Foundation's present facilities, many firms use the Foundation for short-term investigations ; but the director, in noting that the external income of the Foundation is now about 57 per cent of the total revenue, while investment income has decreased by 18 per cent since 1938 and costs have almost doubled, points out that in consequence the Foundation's ability to initiate and sustain investigation in fields of provincial importance, rather than of immediate concern to an industry or a firm, is diminishing. He expresses his firm conviction that societies will prosper in the future in so far as they are willing to authorize research expenditure on a reasonably liberal and long-term basis.

Reviewing the work carried on during the year, the report refers to an investigation undertaken in the Division of Biochemistry to explore the possibilities of using Canadian linseed oil in the manufacture of shortening. Much effort has been devoted to the causes of the objectionable flavour developed by the hydrogenated oil on storage, and this work has led to a wider use of the Beckman ultra-violet spectrophotometer in the laboratories of the Foundation. Fellowships have been established in the Division for the investigation of problems associated with the production of sole leather, and for the development of pharmaceutical products. In the Division of Chemistry, the general organic laboratory was concerned with the investigation of short-term problems submitted by more than seventy firms. A section for statistical quality control was established at the beginning of the year in an effort to make available to industrialists in the Province methods which had proved of great value in the manufacture of munitions. Washable papers of two qualities have been developed under the Canadian Wallpaper Manufacturers' Fellowship, while in the laboratory supported by the Consumers' Gas Co. of Toronto, attention has been concentrated on more economical mothods for the further purification of city gas. A dental materials research laboratory has studied reactions involved when plastics of the methyl metha crylate type are used in manufacturing dentures, and in the Moore Corporation Fellowship improved formulæ have been developed for the production of hot-melt inks for carbon paper, and a new type of ink is also being developed. The Standard Chemical Co., Ltd., has established a fellowship for the study of cellulose derivatives; the Sterling Rubber Co. Fellowship, which led to the development of pilot. plant for the manufacture of plastics from wood, was terminated in September. The facilities of the Department of Metallurgy have been radically re-arranged.

The Department of Parasitology continued its work on the blood parasites of ruffed grouse, and the strain of malaria discovered in ruffed grouse last year has been transferred to birds raised in captivity and to canaries, ducks and turkeys. In the Department of Physiography more time has been given to writing up in permanent form the results of the investigation of the physiography of southern Ontario. In the Textiles Department experience gained during the War in developing and testing fabrics for specific functions is already being used to advantage in peace-time projects. The York Knitting Mills Fellowship has concentrated attention on problems associated with the introduction to Canada of the Kray process for producing unshrinkable wool, and the Canadian Industries Ltd. Fellowship is devoted to a study of the fundamental characteristies of nylon yarn and fabries.

\section{PRECISION-GAUGE LABORATORIES IN THE UNITED STATES $/ 5 / 2$}

\begin{abstract}
A
REPORT in Industrial and Engineering Chemistry of getober describes an interesting and importan defflopent in the establishment of precisiongan laboratories throughout the United Stafls the fining and inspection. This experiment shoifs not only be noted in British plans for university expansion, but may also provide a more convincing reason for the success of the scientific instruments industry in the United States than that of the existence of large consuming firms, to which F. Rothbarth in the Economic Journal attributes the profitableness of the mass production of scientific instruments in the United States.
\end{abstract}

The new development goes back to the establishment of precision-gauge laboratories in the First World War to eliminate troubles due to faulty precision-machine materials through the use of inaccurate or worn gauges. At that time the idea was conceived of maintaining permanent laboratories with regular training facilities under the administration of colleges and universities. The first of these laboratories was set up at Stanford University in 1930, with surplus stocks gathered from arsenals. The success of the project led to expansion of the programme, with a second ordnance educational unit established at the University of Michigan in 1936. In 1940 there were nine laboratories in operation, and during the Second World War these were expanded and used entirely by the Ordnance Department. With the end of the War, the laboratories are once again operating in conjunction with the univer. sities ; in addition to the two mentioned, the major laboratories are located at New York University, Georgia School of Technology, University of Cincinnati, Washington University, Illinois Institute of Technology, Carnegie Institute of Technology, and Case School of Applied Science. Operations are now in progress to convert laboratories set up in the other four ordnance districts during the War to similar ordnance-educational units, as well as to establish additional organisations in the districts where use of the laboratories is especially heavy.

The precision-gauge laboratories are set up, with the institution providing space, light, heat, furniture, and security for the equipment. The schools furnish study courses on precision measurement and inspection, and they can use the equipment in research and consultation, and in standard reference laboratories for the inspection and checking of precision equipment for industry. Provision is made for co-operation in industrial research projects. As non-profit organisations the precision-gauge laboratories can act as referees in disagreements over the precision of tolerances in gauges or even in parts purchased from manufacturers. The Ordnance Department has the use of the laboratories for training students, and each institution is expected to organise an Ordnance unit, the use of the laboratory reverting exclusively to Ordnance in time of war.

One of these laboratories is administered by the Armour Research Foundation of the Illinois Institute of Technology, under the direction of N. C. Penfold, head of the Mechanical Engineering Division of the foundation. The laboratory is housed in the Engineering Building in a room air-conditioned to $68^{\circ} \pm 1^{\circ} \mathrm{F}$. and a relative humidity of 45 per cent. Among major items of equipment are gauge blocks, 